\title{
Prognostic Value of Pretreatment HER2 Status in Gastric Cancer Patients Treated with Postoperative Chemoradiotherapy
}

\author{
Ozan Cem GÜLER, ${ }^{1}$ Mustafa KANDAZ,, Zümrüt BAHAT, ${ }^{1}$ Emine CANYILMAZ, ${ }^{1}$ Emine ÇAKIR, ${ }^{2}$ \\ Adnan YÖNEY, ${ }^{1}$
}

'Department of Radiation Oncology, Karadeniz Technical University, Trabzon-Turkey

${ }^{2}$ Department of Pathology, Karadeniz Technical University, Trabzon-Turkey

\begin{abstract}
OBJECTIVE
Our purpose was to evaluate the prognostic or predictive importance of HER2 status in gastric cancer patients treated with postoperative chemoradiotherapy.

\section{METHODS}

We retrospectively analyzed the records of 49 gastric cancer patients treated with curative intent between April 2012 and January 2017; we also assessed the impact of HER2 status on prognosis and treatment outcomes.

\section{RESULTS}

During a median follow-up period of 14.6 months (range, 4.0-56.97 months), two patients (4\%) had local recurrence and 21 patients (43\%) developed distant metastasis. We found no statistically significant difference in metastasis frequency rates between HER2 negative $(-)$ and positive $(+)$ patients. The median overall survival (OS) and disease-free survival (DFS) for the whole group were 24.9 and 24.2 months, respectively. Although there was no significant difference in OS and DFS according to HER2 status, there was a negative trend in OS $(\mathrm{p}=0.451)$ and DFS $(\mathrm{p}=0.633)$ in HER2 $(+)$ patients.
\end{abstract}

\section{CONCLUSION}

Although our study did not demonstrate any statistically significant importance of HER2 status in gastric cancer patients treated with postoperative chemoradiotherapy, the median OS of 13 months in HER2 (+) patients and 24.9 months for HER2 (-) patients warranted randomized trials with larger cohorts.

Keywords: Chemoradiotherapy; gastric cancer; HER2; radiotherapy.

Copyright $\odot$ 2017, Turkish Society for Radiation Oncology

\section{Introduction}

Gastric cancer is the third most common cause of cancer-related mortality worldwide.[1] Although the main curative treatment strategy for this disease is surgery, adjuvant treatment is essential because of the risk of local recurrence.[2,3] Adjuvant treatment options may vary with countries. Postoperative chemoradiotherapy is widely used in the US based on data from the Intergroup (INT)-0116 study, whereas only postoperative chemotherapy regimens (particularly in patients with D2 dissection) are common in Japan and Southern Europe.[4,5] In Europe, neoadjuvant chemotherapy is used more frequently.[6] Radiotherapy has potential 
to treat metastatic diseases, and it is used for palliative treatment. In Turkey, the most common treatment is postoperative chemoradiotherapy.

Targeted therapies are commonly used for other cancer types such as breast cancer.[7,8] Its application in the treatment of gastric cancer is still investigated. Approximately $7 \%-22 \%$ of gastric cancers overexpress human epidermal growth factor receptor 2 (HER2). Data from the INT-0116 trial suggested that the benefit from postoperative chemoradiotherapy may have been limited to the $90 \%$ of patients without HER 2 amplification. They concluded that overexpression of HER2 may be associated with radiation resistance [4]. Trastuzumab has been approved for HER2 positive $(+)$ advanced gastric cancer patients. Nevertheless, the role of this agent remains unclear because there were conflicting results in gastric cancer patients treated with postoperative chemoradiotherapy. $[4,9]$

In this study, we retrospectively analyzed gastric cancer patients treated with postoperative chemoradiotherapy. We divided patients into two groups according to their HER2 status to determine whether HER2 positivity has any prognostic or predictive importance in these patients both for local control and survival.

\section{Materials and Methods}

\section{Patients and Treatment}

We retrospectively analyzed records of more than 300 patients with biopsy-proven gastric cancer treated in our department since 2007. We excluded patients with unknown HER2 status or with metastatic disease at study initiation. The study population included 49 gastric cancer patients treated with curative intent between April 2012 and January 2017. We received the approval of the institutional review board for this retrospective analysis (Project No: 2017-50).

All patients underwent routine initial clinical staging before operation, including a detailed physical examination, endoscopic examination, complete blood count, blood chemistry test, and computerized tomography of the abdomen. We staged the patients according to the American Joint Committee on Cancer 7th Edition 2010.

The patients were treated according to the clinical protocol described in the INT-0116 trial. Chemotherapy regimen consisted of 5-fluorouracil $(425 \mathrm{mg} /$ $\mathrm{m}^{2}$ per day) and leucovorin $\left(20 \mathrm{mg} / \mathrm{m}^{2}\right.$ per day) or Capecitabine $\left(825 \mathrm{mg} / \mathrm{m}^{2}\right.$, B.I.D, per day) administered for five days. After the first cycle of chemotherapy, patients were treated with a combination of 3-dimensional conformal or intensity-modulated external beam radiotherapy. Clinical tumor volume included the tumor bed, regional lymph nodes, and safety margins for planning the tumor volume. A total dose of $45 \mathrm{~Gy}$ (1.8 Gy per fraction, per day) was delivered using $18 \mathrm{MV}$ photons for five days. Nine patients $(16 \%)$ were treated with radiation up to 50.4 Gy because of positive surgical margins. The second and third cycles of chemotherapy were administered along with radiotherapy. After radiotherapy, patients were treated with two cycles of adjuvant chemotherapy in the same regimen.

\section{HER2 Analysis}

Tissue specimens were evaluated using immunohistochemistry or FISH, where appropriate, for HER2 gene amplification status. In FISH assay, average HER2 gene copy numbers and average chromosome 17 centromeres were evaluated by counting the numbers of signals for at least 50 interphases. The ASCO/CAP scoring criteria was used: ratios $<1.8$ or HER 2 signals $<4$ were reported as non-amplified; ratios of 1.8-2.2 or HER2 signals between 4 and 6 were reported as borderline amplification; and ratios $>2.2$ or HER 2 signals $>6$ were reported as amplified.

\section{Clinical Follow-up}

The clinical follow-up of patients was performed every three months for two years and every six months after two years up to five years. Recurrence or metastasis was defined as biopsy-proven recurrence or documentation of disease progression on serial imaging studies. Failure patterns were described in two main groups as local recurrence or distant metastasis.

\section{Statistical analysis}

The time to event was calculated as the time interval from the date of surgery to the date of the first finding on clinical or imaging examination that suggested disease recurrence. Overall survival (OS) and diseasefree survival (DFS) were calculated using the KaplanMeier method. The survival curves of subgroups were compared using two-sided log-rank tests. All $\mathrm{p}$ values were two-tailed, and $\mathrm{p}<0.05$ was considered statistically significant.

\section{Results}

\section{Patient Characteristics}

We summarized the patient characteristics in (Table 1). The median age of the patients was 57 (range, 29-78) years. More than half of the patients were males. The most common anatomical site of primary gastric can- 


\begin{tabular}{|c|c|}
\hline & n (\%) \\
\hline Median Age & 57 \\
\hline \multicolumn{2}{|l|}{ HER2 } \\
\hline Positive & $8(16)$ \\
\hline Negative & $41(84)$ \\
\hline \multicolumn{2}{|l|}{ Sex } \\
\hline Female & $17(35)$ \\
\hline Male & $32(65)$ \\
\hline \multicolumn{2}{|l|}{ Anatomical Site } \\
\hline Proximal - Middle & $30(61)$ \\
\hline Distal & $19(39)$ \\
\hline \multicolumn{2}{|l|}{ T Stage } \\
\hline $\mathrm{T} 1-\mathrm{T} 2$ & $6(12)$ \\
\hline $\mathrm{T} 3-\mathrm{T} 4$ & $43(88)$ \\
\hline \multicolumn{2}{|l|}{ N Stage } \\
\hline N0-N1 & $28(57)$ \\
\hline $\mathrm{N} 2-\mathrm{N} 3$ & $21(43)$ \\
\hline \multicolumn{2}{|l|}{ Histology } \\
\hline Adenocarcinoma & $44(89)$ \\
\hline Mucinous & $5(11)$ \\
\hline \multicolumn{2}{|l|}{ RT Dose } \\
\hline 45 Gy & $40(82)$ \\
\hline 50.4 Gy & $9(18)$ \\
\hline \multicolumn{2}{|l|}{ Surgical margins } \\
\hline Negative & $40(82)$ \\
\hline Positive & $9(16)$ \\
\hline \multicolumn{2}{|l|}{ Chemotherapy } \\
\hline FUFA & $36(74)$ \\
\hline Capecitabine & $12(24)$ \\
\hline None & $1(2)$ \\
\hline
\end{tabular}

cer was middle third, and majority of the patients had adenocarcinoma. Most patients had undergone total gastrectomy and D2 dissection with negative surgical margins and were treated with a total of 45 Gy concurrent chemoradiotherapy with FUFA. One patient (2\%) refused chemotherapy and $12(24 \%)$ patients were treated with concurrent Capecitabine. All patients received at least one cycle of adjuvant chemotherapy.

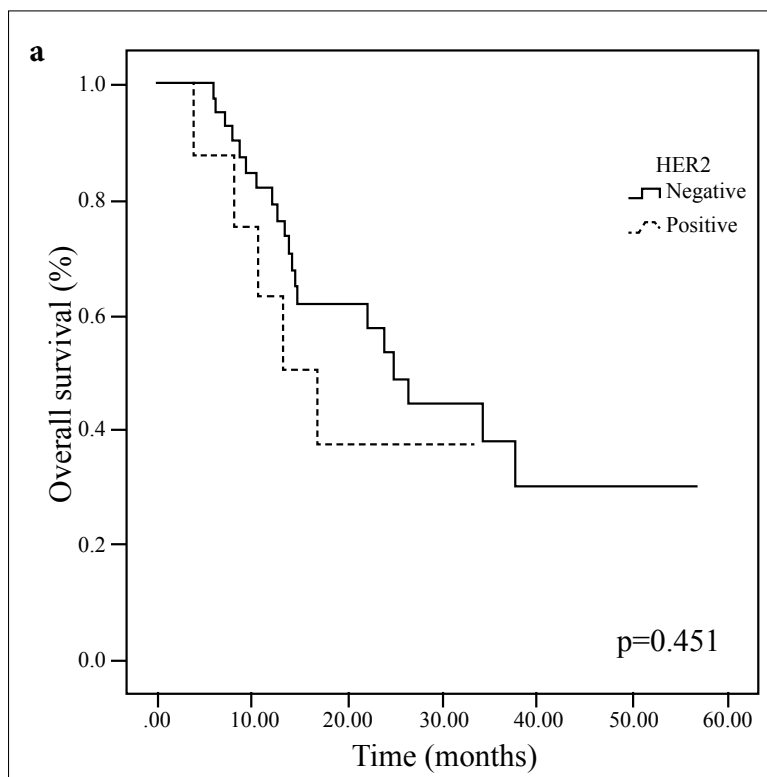

Fig. 1(a) Overall survival curves for HER2 positive and negative patients.

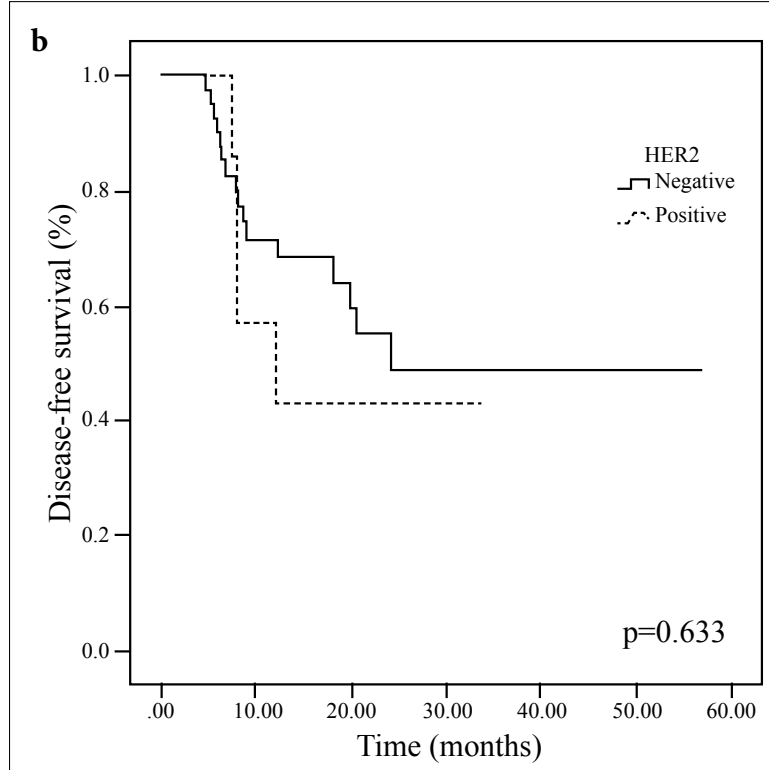

Fig. 1(b) Disease-free survival curves for HER2 positive and negative patients.

\section{Local Recurrences and Distant Metastasis}

During a median follow-up period of 14.6 (range, 4.056.97) months, two patients (4\%) had local recurrence and 21 patients (43\%) developed distant metastasis. Local recurrence was observed in two patients (4\%) in the HER2 (-) group, but not in the HER2 (+) group. 
We could not perform statistical analysis between the groups for local recurrence rates due to low event rates. Distant metastasis was observed in 17 patients (35\%) with HER2 (-) and four patients (8\%) with HER2 (+). There was no statistically significant difference in metastasis frequency rates.

\section{Survival}

The median OS and DFS for the whole group were 24.9 (12.9-36.9) months and 24.2 months, respectively. The median OS for HER2 (-) and (+) patients were 24.9 (range, 19.2-30.7) months and 13.0 (range, 5.0-21.0) months, respectively. Although HER2 (-) patients had a numerically better median OS, this difference did not have statistical significance $(\mathrm{p}=0.451)$. There was also no statistically significant difference in DFS between HER2 $(+)$ and $(-)$ patients ( $\mathrm{p}=0.633$; Fig. 1 ).

In univariate analysis, gender (male vs. female), $\mathrm{T}$ stage (T1-2 vs. T3-4), and surgery (total vs. subtotal) did not show any significant difference for both OS and DFS. N-stage (N0-1 vs. N2-3) was predictive for DFS $(\mathrm{p}=0.005)$, and dissection status (D1 vs. D2) was statistically significantly favoring D2 for OS ( $\mathrm{p}=0.038)$.

\section{Discussion}

Our study investigated the prognostic importance of HER2 status in gastric cancer patients treated with postoperative chemoradiotherapy. Although the main treatment for gastric cancer is tumor resection and lymphadenectomy, adjuvant treatment is a necessity because of the high relapse rates.[10,11] The pivotal INT-0116 trial demonstrated that the use of 5-FU-based adjuvant chemoradiotherapy increased DFS and OS along with the increased treatment-related toxicity.[12]

In the era of molecular oncology, targeted therapies have become more interesting. One of these therapies is trastuzumab, which is an anti-HER2 monoclonal antibody.[13] HER2 is a member of the epidermal growth factor receptor family of tyrosine kinases, which are involved in tumor proliferation, adhesion, differentiation, migration, and apoptosis.[14] Trastuzumab has been approved for HER2 $(+)$ metastatic gastric cancer. In ToGA trial, a combination of chemotherapy and trastuzumab demonstrated a significant OS benefit in metastatic gastric cancer patients.[15] Its value as a prognostic factor of HER2 in gastric cancer is controversial and may vary based on whether the patient receives chemotherapy. For instance, Terashima et al.[16] investigated the HER2 status in gastric cancer and found that HER2 was not a prognostic marker in the absence of chemotherapy. In addition, patients with HER2 (+) gastric cancer showed an improved outcome with chemotherapy. The association of HER2 status with prognosis in a total of 1562 gastric cancer patients undergoing R0 resection was also investigated by Shen et al.[17] They reported that there were no significant associations between HER2 status and DFS or OS in multivariate analysis.

In our study, the incidence of HER2 positivity was $16 \%$. Although our cohort was relatively small and could not represent the whole population, the incidence was consistent with results of previous studies. Moreover, adenocarcinoma was the only histology in the HER2 (+) patients, and majority of the patients were male. We did not acquire any data about male predominance or adenocarcinoma histology association with HER2 (+) gastric cancer. Therefore, it is hard to say whether these findings are incidental or related to the disease.

A similar study, the INT-0116 clinical trial, retrospectively focused on the available tissue specimens for HER2 gene amplification and investigated the relation between HER2 expression and outcomes. They concluded that there was a significant interaction between HER2 amplification and treatment with respect to both DFS $(p=0.020)$ and OS $(p=0.034)$. Patients whose tumors had HER2 gene amplification had shorter DFS and OS (13 and 16 months, respectively) compared with the patients whose tumors lacked HER2 gene amplification ( 34 and 44 months; $\mathrm{p}=0.026$ and 0.025 , respectively). The analysis of HER2 (+) patients indicated no significant difference between treatment regimens. Here the absence of benefit from adjuvant chemoradiotherapy should be interpreted with caution in view of the small patient sample [28 HER2 (+) patients]. The same study found no significant difference in OS or DFS based on HER2 amplification status among patients who only underwent surgery. Therefore, they concluded that HER2 may not be an insufficient prognostic marker of poor outcome in the absence of treatment.[18]

The MAGIC trial evaluated 415 specimens for HER2 status. The systemic treatment regimen consisted of anthracycline-based chemotherapy. HER2 status was not a prognostic factor in this study and did not have any predictive value for screening the treatment response to anthracycline-based chemotherapy.[19] Likewise, the ACTS-GC study did not demonstrate any influence of HER2 expression/amplification on the prognosis of gastric cancer patients.[16] In their in vitro study, Pietras et al.[20] demonstrated that inhibit- 
ing HER2 with antibody caused significant changes in the radiosensitivity of tumor cells. Declining the radioresistance by HER2 antibody may improve radiationinduced apoptosis.

A systematic analysis of data from Danish literature performed with 42 publications and over 12000 patients concluded that HER2 had a potential role as a negative prognostic factor in gastric cancer. In addition, they reported that HER2 overexpression and/or amplification may be a molecular abnormality linked to this disease development.[21]

In addition to the abovementioned studies, $\mathrm{Li}$ et al.[22] investigated the effectiveness of locoregionally administered trastuzumab armed with astatine-211 (211At-trastuzumab) against HER2 (+) peritoneal metastasis of gastric cancer in a xenograft mouse model. They concluded that locoregionally administered 211 At-trastuzumab significantly prolonged the survival time of HER2 (+) peritoneal metastasis of gastric cancer mice compared with control treatments.

Our study has some limitations. First, as with any retrospective study, unpredictable biases may have influenced our results. Second, the limited cohort size makes it difficult to generalize the results to whole population. Nevertheless, we had a homogenous group of gastric cancer patients treated with the same protocol, and our study may help evaluate the prognostic significance of molecular therapies in the presence of conventional chemoradiotherapy protocols.

\section{Conclusion}

Although our study did not indicate any statistically significant importance of HER2 status in gastric cancer patients treated with postoperative chemoradiotherapy, the results suggested that there was a trend in favor of HER2 (-) patients. This study is not beyond hypothesis generation and needs to be confirmed before a routine assay of HER2 expression is used as a means of patient selection. Therefore, randomized studies with larger cohorts are warranted to acquire more reliable data on this important topic.

\section{Disclosures}

Ethics Committee Approval: This study was conducted inaccordance with local ethical rules.

Peer-review: Externally peer-reviewed.

Conflict of Interest: None declared.

Authorship contributions: Concept - O.C.G, A.Y; Design - O.C.G, A.Y; Supervision - A.Y; Materials - M.K, Z.B, E.C;
Data collection \&/or processing - Z.B, E.C, E.Ç; Analysis and/or interpretation - E.C, Z.B; Literature search - M.K; Writing - O.C.G, A.Y; Critical review - O.C.G, M.K, Z.B, E.C, E.Ç, A.Y

\section{References}

1. Torre LA, Bray F, Siegel RL, Ferlay J, Lortet-Tieulent J, Jemal A. Global cancer statistics, 2012. CA Cancer J Clin 2015;65(2):87-108.

2. İzmirli M, Kilic K, Yilmazer G, Nart M. A retrospective analysis of prognostic factors and treatment results of gastric adenocarcinomas treated with postoperative chemoradiotherapy. Turk J Oncol 2014;29(4):137-47.

3. Sökücü N, Balık E. Mide Kanseri Tedavisinde Güncel Algoritma. Turkiye Klinikleri J Gen Surg-Special Topics 2013;6(3):39-47.

4. Smalley SR, Benedetti JK, Haller DG, Hundahl SA, Estes NC, Ajani JA, et al. Updated analysis of SWOGdirected intergroup study 0116: a phase III trial of adjuvant radiochemotherapy versus observation after curative gastric cancer resection. J Clin Oncol 2012;30(19):2327-33

5. Sakuramoto S, Sasako M, Yamaguchi T, Kinoshita T, Fujii M, Nashimoto A, et al; ACTS-GC Group. Adjuvant chemotherapy for gastric cancer with $S-1$, an oral fluoropyrimidine. N Engl J Med 2007;357(18):1810-20.

6. Cunningham D, Allum WH, Stenning SP, Thompson JN, Van de Velde CJ, Nicolson M, et al; MAGIC Trial Participants. Perioperative chemotherapy versus surgery alone for resectable gastroesophageal cancer. $\mathrm{N}$ Engl J Med 2006;355(1):11-20.

7. Baselga J, Tripathy D, Mendelsohn J, Baughman S, Benz CC, Dantis L, et al. Phase II study of weekly intravenous trastuzumab (Herceptin) in patients with HER2/neuoverexpressing metastatic breast cancer. Semin Oncol 1999;26(4 Suppl 12):78-83.

8. Rayson D, Lutes S, Walsh G, Sellon M, Colwell B, Dorreen $M$, et al. Trastuzumab beyond progression for HER2 positive metastatic breast cancer: progressionfree survival on first-line therapy predicts overall survival impact. Breast J 2014;20(4):408-13.

9. Maresch J, Schoppmann SF, Thallinger CM, Zielinski CC, Hejna M. Her-2/neu gene amplification and over-expression in stomach and esophageal adenocarcinoma: from pathology to treatment. Crit Rev Oncol Hematol 2012;82(3):310-22.

10. Pak Y. Radyoterapinin mide kanseri tedavisindeki yeri. Turkiye Klinikleri J Surgery 2000;5(4):196-202.

11. Oruc A, Karabulut Gül S, Mayadaglı A. Radiotherapy of stomach cancer. Turkiye Klinikleri J Med OncolSpecial Topics 2012;5(3):30-6. 
12. Macdonald JS, Smalley SR, Benedetti J, Hundahl SA, Estes NC, Stemmermann GN, et al. Chemoradiotherapy after surgery compared with surgery alone for adenocarcinoma of the stomach or gastroesophageal junction. N Engl J Med 2001;345(10):725-30.

13. Apicella M, Corso S, Giordano S. Targeted therapies for gastric cancer: failures and hopes from clinical trials. Oncotarget 2017;8(34):57654-69.

14. Gravalos C, Jimeno A. HER2 in gastric cancer: a new prognostic factor and a novel therapeutic target. Ann Oncol 2008;19(9):1523-9.

15. Bang YJ. Advances in the management of HER2-positive advanced gastric and gastroesophageal junction cancer. J Clin Gastroenterol 2012;46(8):637-48.

16. Terashima M, Kitada K, Ochiai A, Ichikawa W, Kurahashi I, Sakuramoto S, et al; ACTS-GC Group. Impact of expression of human epidermal growth factor receptors EGFR and ERBB2 on survival in stage II/III gastric cancer. Clin Cancer Res 2012;18(21):59926000.

17. Shen GS, Zhao JD, Zhao JH, Ma XF, Du F, Kan J, et al. Association of HER2 status with prognosis in gastric cancer patients undergoing R0 resection: A large-scale multicenter study in China. World J Gastroenterol 2016;22(23):5406-14.
18. Gordon MA, Gundacker HM, Benedetti J, Macdonald JS, Baranda JC, Levin WJ, et al. Assessment of HER2 gene amplification in adenocarcinomas of the stomach or gastroesophageal junction in the INT-0116/ SWOG9008 clinical trial. Ann Oncol 2013;24(7):175461.

19. Okines AF, Thompson LC, Cunningham D, Wotherspoon A, Reis-Filho JS, Langley RE, et al. Effect of HER2 on prognosis and benefit from peri-operative chemotherapy in early oesophago-gastric adenocarcinoma in the MAGIC trial. Ann Oncol 2013;24(5):1253-61.

20. Pietras RJ, Poen JC, Gallardo D, Wongvipat PN, Lee HJ, Slamon DJ. Monoclonal antibody to HER-2/neureceptor modulates repair of radiation-induced DNA damage and enhances radiosensitivity of human breast cancer cells overexpressing this oncogene. Cancer Res 1999;59(6):1347-55.

21. Jørgensen JT, Hersom M. HER2 as a Prognostic Marker in Gastric Cancer-A Systematic Analysis of Data from the Literature. J Cancer 2012;3:137-44.

22. Li HK, Morokoshi Y, Nagatsu K, Kamada T, Hasegawa S. Locoregional therapy with a-emitting trastuzumab against peritoneal metastasis of human epidermal growth factor receptor 2-positive gastric cancer in mice. Cancer Sci 2017;108(8):1648-56. 